\title{
Chronic lymphocytic leukemia skin infiltration mimicking an ICD pocket infection: a case report
}

M. Snorek ${ }^{1}$, A. Bulava ${ }^{1,2,3^{*}}$ and I. Vonke

\begin{abstract}
Background: We are presenting a case report on an unreported and unusual cutaneous manifestation of chronic lymphocytic leukemia in a patient with an implantable cardioverter-defibrillator (ICD).

Case presentation: A 65-year-old man with a history of chronic lymphocytic leukemia (CLL), previously treated with chlorambucil, was referred in October 2013 for extraction of a single chamber ICD due to a suspected device-related infection in the pulse generator area (left-hand side of Fig. 1). The ICD system (Current VR, St. Jude Medical, USA) had been implanted in November 2009. The patient complained of painless erythema with pruritus in the pocket area. Inflammatory blood parameters were C-reactive protein $17.3 \mathrm{mg} / \mathrm{L}$ and leucocytes $29.0 \times 10^{9} / \mathrm{L}$. Due to the atypical appearance of the pocket area we did not extract the device. Instead, we created an exploratory excision in the skin induration, which had been present for approximately 6 weeks, and conducted a microbiological and histological examination. All cultivation examinations were negative. However, we did histologically show skin infiltration by CD-5 positive low-grade B-cell chronic lymphocytic leukemia/small lymphocytic lymphoma (B-CLL/SLL). Re-initiation of chemotherapy was not necessary and the skin induration completely disappeared within 2 months (right-hand side of Fig. 1).
\end{abstract}

Conclusions: Complete removal of an ICD system carries considerable risk. In patients with a history of hematological disease, it is crucial to exclude cutaneous manifestations of the disease prior to device removal.

Keywords: Chronic lymphocytic leukemia, Implantable cardioverter-defibrillator, Pocket infection

\section{Background}

We are presenting a case report on an unreported and unusual cutaneous manifestation of a chronic lymphocytic leukemia in a patient with an implantable cardioverter-defibrillator.

\section{Case presentation}

A 65-year-old man with a history of chronic lymphocytic leukemia (CLL), previously treated with chlorambucil, but currently not on active treatment, was referred in October 2013 for extraction of a single chamber implantable cardioverter-defibrillator (ICD) because of a

\footnotetext{
*Correspondence: alanbulava@seznam.cz

'Department of Cardiology, Ceske Budejovice Hospital, Ceske Budejovice, Czech Republic

${ }^{2}$ Faculty of Health and Social Sciences, University of South Bohemia, Ceske Budejovice, Czech Republic

Full list of author information is available at the end of the article
}

suspected device-related infection in the pulse generator area (left-hand side of Fig. 1). The ICD system (Current VR, St. Jude Medical, USA) had been implanted in November 2009 for primary prevention of sudden cardiac death in the setting of idiopathic dilated cardiomyopathy with low left ventricular ejection fraction (25\%). The patient complained of painless erythema with intense pruritus in the pocket area. Inflammatory blood parameters were C-reactive protein $17.3 \mathrm{mg} / \mathrm{L}(\mathrm{ULN}<5)$, procalcitonin $0.2 \mathrm{ng} / \mathrm{ml} \quad(\mathrm{ULN}<0.5)$ and leucocytes $29.0 \times 10^{9} / \mathrm{L}(\mathrm{ULN}<10)$, and with $84 \%$ lymphocytes. The patient had no fever and his body temperature was in range of $36.5-36.9^{\circ} \mathrm{C}$. Due to the atypical appearance of the pocket area we deferred extracting the device. Instead, we created an exploratory excision of the skin induration, which had been present for approximately 6 weeks, and conducted a microbiological and histological examination. Both aerobic and anaerobic cultivation examinations were 


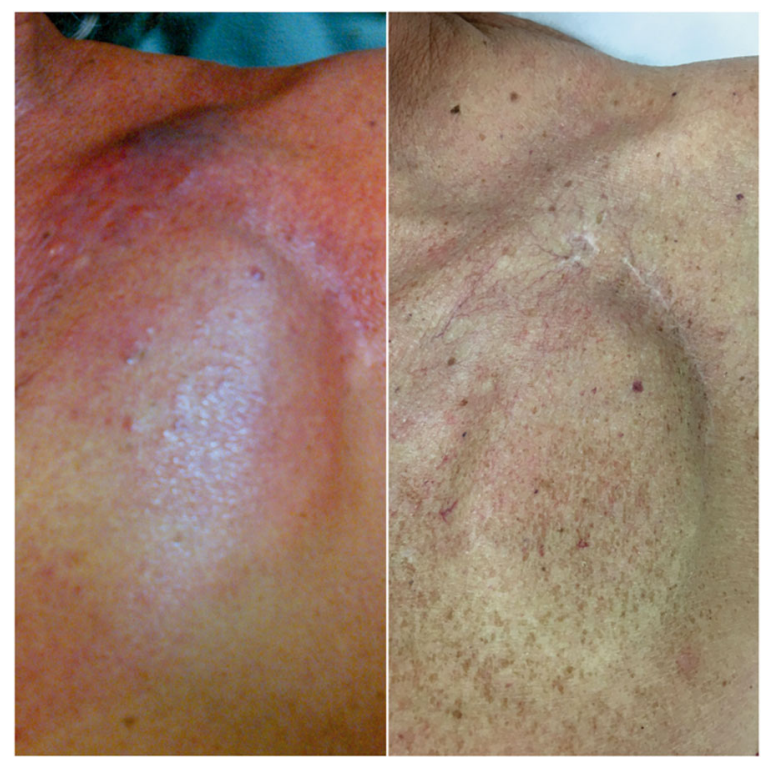

Fig. 1 Left-hand side: Painless erythema and mild induration over the device pocket suspicious of device-related infection. Right-hand side: skin induration spontaneously disappeared over following two months

negative. However, skin infiltration by CD-5 positive lowgrade B-cells was found, which suggested a diagnosis of chronic lymphocytic leukemia/small lymphocytic lymphoma (B-CLL/SLL). Re-initiation of chemotherapy was not necessary because of the disease was considered stable and the skin induration spontaneously and completely disappeared (right-hand side of Fig. 1) over following 2 months and no relapse of symptoms has been observed till present time.

\section{Discussion}

Infectious complications, following cardiac implantable electronic device (CIED) implantation have steadily increased since it first entered clinical practice and are associated with significant mortality. Important hostrelated risk factors presented in a recently published meta-analysis included: diabetes mellitus, renal disease, chronic obstructive pulmonary disease, corticosteroid use, malignancy, heart failure, and anticoagulant drug use. Procedure-related risk factors included lack of antibiotic prophylaxis, replacement/revision procedures, non-infectious post-operative complications (including dislodged leads and hematoma), temporary pacing, and procedure duration. Average device infection rates have been reported between 1-1.3\% [1].

Pacemaker component allergy is a relatively uncommon cause of erythema and pain at the pacemaker implantation site. Diagnosis of a pacemaker component allergy first requires awareness of the problem and then thorough allergy testing with the appropriate allergy test kit provided by the manufacturer. Pacemaker component allergy can present as painful erythema with pruritus covering a large area around the device and may occur months after the implantation procedure. Therapy with a topical corticoid may permanently resolve the skin reaction; otherwise, a more extensively coated or a gold-plated device may need to be implanted in place of the original device [2].

A very rare condition, which can mimic a pacemaker pocket infection, is breast carcinoma. It has been reported in both male and female patients. A firm lesion with signs of skin erosion can be observed near the pacemaker pocket; however, C-reactive protein, white-cell count, and other routine blood tests can be normal [3].

\section{Conclusions}

Removal of CIEDs and all associated leads carries considerable risks. Therefore, in patients with a history of hematological disease, it is crucial to exclude cutaneous manifestations of the disease prior to device removal. Other conditions mimicking pocket infection include breast cancer or pacemaker component allergy.

\section{Abbreviations}

B-CLL: B-cell chronic lymphocytic leukemia; CIED: Cardiac implantable electronic device; CLL: Chronic lymphocytic leukemia; ICD: Implantable cardioverter-defibrillator; SLL: Small lymphocytic lymphoma; ULN: Upper limit of normal

\section{Acknowledgements}

Pavla VITKOVA, Department of Pathology, Ceske Budejovice Hospital, B. Nemcove 585/54, 37001 Ceske Budejovice, Czech Republic. PV performed the histological examination.

Cardiocenter Ceske Budejovice Foundation for financial support of manuscript publication.

\section{Funding}

Foundation Cardiocenter Ceske Budejovice financially supported the publication costs of the manuscript.

Availability of data and materials Not applicable.

\section{Authors' contributions}

MS: patient followed-up and contributed to writing the manuscript. AB: case senior cardiologists, performed the procedure and contributed to writing the manuscript, performs all duties of the corresponding author. IV: interpreted patient findings regarding the hematological disease. All authors read and approved the final manuscript.

\section{Competing interests}

The authors declare that they have no competing interests.

\section{Consent for publication}

Written informed consent for the publication of all the information contained in the case report and any accompanying images has been obtained from the patient.

\section{Ethics approval and consent to participate} Not applicable.

\section{Publisher's Note}

Springer Nature remains neutral with regard to jurisdictional claims in published maps and institutional affiliations. 


\section{Author details}

'Department of Cardiology, Ceske Budejovice Hospital, Ceske Budejovice, Czech Republic. ${ }^{2}$ Faculty of Health and Social Sciences, University of South Bohemia, Ceske Budejovice, Czech Republic. ${ }^{3}$ Faculty of Medicine and Dentistry, Palacky University, Olomouc, Czech Republic. ${ }^{4}$ Department of Hematology, Ceske Budejovice Hospital, Ceske Budejovice, Czech Republic.

Received: 10 January 2017 Accepted: 11 March 2017

Published online: 24 March 2017

\section{References}

1. Polyzos KA, Konstantelias AA, Falagas ME. Risk factors for cardiac implantable electronic device infection: a systematic review and meta-analysis. Europace. 2015;17(5):767-77.

2. Citerne O, Gomes S, Scanu P, Milliez P. Painful Eczema mimicking pocket infection in a patient with an ICD: a rare cause of skin allergy to nickel/ cobalt alloy. Circulation. 2011:123(11):1241-2.

3. De Mattia L, Brieda M, Dametto E. A carcinoma of the breast mimicking a pacemaker pocket infection. Europace. 2011;13(2):220.

Submit your next manuscript to BioMed Central and we will help you at every step:

- We accept pre-submission inquiries

- Our selector tool helps you to find the most relevant journal

- We provide round the clock customer support

- Convenient online submission

- Thorough peer review

- Inclusion in PubMed and all major indexing services

- Maximum visibility for your research

Submit your manuscript at www.biomedcentral.com/submit
Biomed Central 